Fikroh : Jurnal Pemikiran dan Pendidikan Islam

Volume. 14, Number. 1, Januari 2021

p-ISSN : 2087-7501, e-ISSN : 2715-4459

Hlm : 43-64

Journal Home Page : https://jurnal.stai-alazharmenganti.ac.id/index.php/fikroh

\title{
MODEL PENGEMBANGAN KURIKULUM MADRASAH HADRAMAUT DI PONDOK PESANTREN DARUL FAQIH MALANG
}

\author{
Faris Khoirul Anam \\ Universitas Negeri Malang, Malang, Indonesia \\ faris.fs@um.ac.id
}

\begin{abstract}
Model for development of madrasah curriculum hadramaut in pondok pesantren darul faqih malang. This paper provides an overview of the model of Hadramaut Madrasah curriculum development in Darul Faqih Islamic boarding school Malang, starting from constructing the planning, implementation, and evaluation of Hadramaut Madrasah curriculum, theoretically from the concept, to the Darul Faqih Islamic Boarding School. In general, the model of Hadramaut Madrasah curriculum development, which includes planning, implementation, and evaluation, is intended to be carried out in pesantren under the paying of its vision and mission. The Hadramaut education model is a harmonious and moderate education, so that when developed in Islamic boarding schools it can be said to be suitable and appropriate. Although there are many activities carried out in Islamic boarding schools, students can develop their abilities or potential and be bridged to continue their studies at Hadramaut.
\end{abstract}

Keywords: Model; Curriculum; Madrasa; Hadramaut; Boarding school

\begin{abstract}
Abstrak
Model pengembangan kurikulum madrasah hadramaut di pondok pesantren darul faqih malang. Tulisan ini memberikan gambaran tentang model pengembangan kurikulum madrasah Hadramaut di pondok pesantren Darul Faqih Malang, mulai dari mengkonstruksi perencanaan, pelaksanaan, dan evaluasi kurikulum Madrasah Hadramaut, secara teoritis dari konsep, pada lembaga pendidikan pondok Pesantren Darul Faqih. Secara umum model pengembangan kurikulum Madrasah Hadramaut, yang meliputi perencanaan, pelaksanaan, dan evaluasi, diikhtiarkan untuk dilakukan di pesantren dibawah payung visi dan misinya. Model pendidikan Hadramaut merupakan Pendidikan yang harmoni dan moderat, sehingga ketika dikembangkan di pondok pesantren dapat dikatakan cocok dan tepat. Meskipun banyak kegiatan yang
\end{abstract}


dilakukan di dalam pondok pesantren, akan tetapi santri dapat mengembangkan kemampuan ataupun potensi yang dimilikinya dan dijembatani agar bisa melanjutkan studi ke Hadramaut.

Kata kunci: Model; Kurikulum; Madrasah; Hadramaut; Pesantren

\section{A. Pendahuluan}

Model adalah konstruksi yang bersifat teoritis dari konsep. Dalam kegiatan pengembangan kurikulum, model merupakan ulasan teoritis tentang proses pengembangan kurikulum secara menyeluruh atau dapat pula hanya merupakan ulasan tentang salah satu komponen kurikulum. Ada suatu model yang memberikan ulasan tentang keseluruhan proses kurikulum. Akan tetapi, adapula yang hanya menekankan pada mekanisme pengembangannya dan itu pun hanya pada uraian pengembangang organisasinya.

Model pengembangan kurikulum adalah model yang digunakan untuk mengembangkan suatu kurikulum, dimana pengembangan kurikulum dibutuhkan untuk memperbaiki atau menyempurnakan kurikulum yang dibuat untuk dikembangkan sendiri baik dari pemerintah pusat, pemerintah daerah ataupun dari sekolah. Terdapat beberapa model pengembangan, misalnya Model Terbalik Hilda Taba (dimulai dengan melaksanakan eksperimen, diteorikan kemudian diimplementasikan, dengan maksud untuk menyesuaikan antara teori dan praktik), model Oliva, dan model Tyler. Model terakhir ini merupakan model yang paling dikenal bagi perkembangan kurikulum dengan perhatian khusus pada fase perencanaan. Walaupun Tyler mengajukan model pengembangan kurikulum secara komprehensif tetapi bagian pertama dari modelnya (seleksi tujuan) menerima sambutan yang hangat dari para edukator. Ada beberapa langkah pengembangan kurikulum yang diambil oleh model ini, yaitu: (1) Perencanaan kurikulum agar mengidentifikasikan tujuan umum dengan mengumpulkan data dari tiga sumber, yaitu: kebutuhan peserta didik, masyarakat dan subject matter, (2) Mereview dengan cara menyaring melalui dua saringan, yaitu filosofi pendidikan dan psikologi belajar, (3) Menyeleksi pengalaman belajar yang menunjang pencapaian tujuan, (4) Mengorganisasikan pengalaman kedalam unit-unit dan menggambarkan berbagai prosedur evaluasi, (5) Mengarahkan dan menguatkan pengalaman-pengalaman belajar dan mengkaitkannya dengan evaluasi terhadap keefektifan perencanaan dan pelaksanaan, (6) Evaluasi pengalaman belajar, (7) Kesimpulan. 
Berbagai penelitian tentang pengembangan kurikulum pondok pesantren telah disusun. Misalnya adalah Model Pengembangan Kurikulum Pesantren (Studi di Sekolab Tinggi Ilmu Kitab Kuning an-Nur II al-Murtadho Bululawang Malang oleh Edi Sutrisno sebagai tesis di Program Pascarsaja UIN Maliki Malang. Selain itu, terdapat pula beberapa penelitian tentang kurikulum pondok pesantren yang dimuat beberapa jurnal. Beberapa di antaranya adalah sebagai berikut: (1) Implementasi Pengembangan Kurikulum di Pondok Pesantren (Studi Multisitus di Pesantren al-Aqobah dan Pesantren Tarbiyatun Nasyi'in Pacul Gowang Kabupaten Jombang) oleh Agus Prasetyo (Jurnal Iqra: Kajian Ilmu Pendidikan E-ISSN: 2548-7892 \& P - ISSN: 2527-4449 Volume 3, Issue 2, December 2018); (2) Kurikulum dan Sistem Pembelajaran Pondok Pesantren Salafi di Kecamatan Kresek Kabupaten Tangerang Provinsi Banten oleh Kholis Thohir (Analytica Islamica: Vol. 6 No. 1 Januri-Juni 2017); (3) Pola Pengembangan Kurikulum Pesantren (Kasus Al-Mukhlishin Mempawah Kalimantan Barat) oleh Lailial Muhtifah (Jurnal MP Vol XVII No 2 2012/ 1433).

Penelitian tentang model pendidikan yang harmoni dan moderat juga telah banyak dilakukan. Misalnya adalah (1) Implementasi Prinsip at-Tawazun Perspektif Ahlus Sunnah Wal Jama'ah An Nahdiyah dalam Pengembangan Nilai Pendidikan Karakter Siswa Di Madrasah Aliyah Al Azhar Banjarwati Paciran Lamongan oleh Dedy Prasetyo (Jurnal Akademia, Vol 10, No 2, Desember 2012); (2) Pembentukan Karakter Nasionalisme melalui Pembelajaran Pendidikan Aswaja pada Siswa Madrasah Aliyah Al Asror Semarang oleh Sucihatiningsih Dian WP \& Moh Yasir Alimi (Journal of Educational Social Studies / JESS 6 (1) (2017): 7 - 19 Universitas Negeri Semarang; (3) Pendidikan Aswaja Sebagai Upaya Menangkal Radikalisme oleh Didin Wahyudin (Dinamika Penelitian: Media Komunikasi Sosial (Vol. 17, No. 2, November 2017);

Berdasarkan data tersebut dapat dikatakan bahwa penelitian tentang kurikulum pondok pesantren dan pengembangannya memang telah banyak ditemukan. Namunsejauh pengetahuan penulis-kajian yang secara khusus meneliti tentang pengembangan kurikulum Madrasah Hadhramaut di pondok pesantren belum ada yang melakukannya secara khusus. Padahal di sisi lain, melalui beberapa penelusuran sejarah ditemukan fakta bahwa Islam di Nusantara dibawa oleh para juru dakwah dari Hadhramaut. Walisongo sebagai pengembang utama dakwah Islam di Nusantara - terutama Jawa - juga merupakan 
keturunan Hadhramaut. Beberapa kitab yang dikaji di pondok pesantren juga merupakan karya ulama Hadhramaut, demikian pula tradisi-tradisi islami yang berkembang di Nusantara, diyakini juga memiliki akar di Hadhramaut, yang saat ini menjadi salah satu propinsi di Yaman. Pada sisi inilah penulis meyakini urgensitas penelitian ini yang dikemas dalam bentuk pola pengembangan kurikulum yang sedang diikhtiarkan di Pondok Pesantren Darul Faqih Malang. Penelitian tentang pengembangan kurikulum Madrasah Hadhramaut di Pondok Pesantren Darul Faqih Malang dengan pendekatan model pengembangan ala Tyler ini diawali mulai dari perencanaan kurikulum yang berbasis pada kebutuhan peserta didik, masyarakat, dan subject matter atau bahan/ mata pelajaran. Kedua, terkait pelaksanaan pengembangan kurikulum Madrasah Hadramaut di pondok pesantren tersebut. Selanjutnya yang ketiga, bagaimanakah evaluasi pengalaman belajar dan kesimpulannya. Oleh karena itu, dalam penelitian ini peneliti akan mendeskripsikan kekhasan kurikulum Madrasah Hadramaut ini secara umum terlihat pada sejarah, filosofi, dan hubungan eratnya dengan masyarakat muslim Nusantara. Sementara kekhasan khususnya dapat dilihat pada penerapan kurikulum itu di pondok pesantren Darul Faqih Malang, yang meniscayakan evaluasi pengalaman belajar di kemudian hari.

\section{B. Metode Penelitian}

\section{Pendekatan dan Jenis Penelitian}

Penelitian ini merupakan penelitian kualitatif dengan pendekatan deskriptif, yaitu prosedur peneltian yang menghasilkan data deskriptif berupa kata-kata tertulis, lisan dari orang-orang dan perilaku yang diamati, penyusunan dan pengumpulan data, kemudian dianalisa dan diinterpretasi tentang data yang diperoleh. ${ }^{1}$ Peneliti tidak menggunakan metode kualitatif karena permasalahn belum jelas, holistik, kompleks, dinamis, dan penuh makna. Itulah alasan para peneliti tidak menggunakan metode kuantitatif dalam ranah ini dan lebih memilih metode kualiitatif. ${ }^{2}$

\footnotetext{
1 Andi Prastowo, Metode Penelitian Kualitatif Dalam Perspektif Rancangan Penelitian (Jogjakarta: Ar-Ruzz Media, 2012), 186.
} 
Sedangkan jenis penelitian yang digunakan adalah deskriptif-studi kasus. ${ }^{3}$ Metode ini digunakan untuk meneliti status kelompok manusia, suatu objek, suatu set kondisi, atau suatu sistem pemikiran. Penelitian ini dipergunakan untuk memahami lembaga pendidikan Islam yakni pondok pesantren dengan sumber data dari catatan lapangan dan wawancara mendalam (in depth interview), serta dokumentasi. Data-data tersebut dibutuhkan untuk tujuan ketajaman analisis sehingga interpretasi yang dilakukan memperoleh ketepatan.

\section{Subyek penelitian}

Subyek penelitian merupakan asal sumber data itu diperoleh. Pemilihan subyek penelitian (informan) dilakukan dengan teknik purposive sampling dan snowball sampling. ${ }^{4}$ Adapun Sumber data atau informan dalam penelitian ini adalah pengurus Pondok Pesantren Darul Faqih Malang.

\section{Latar Penelitian}

Penelitian ini dilaksanakan pada tanggal 2 Oktober - 15 Desember 2019 di Pondok Pesantren Darul Faqih Malang. Pesantren ini terletak di Jl. Gapura 197 Dusun Santren Desa Pandanlandung Kecamatan Wagir Kabupaten Malang. Pondok Pesantren Darul Faqih dipilih sebagai studi kasus penelitian karena pesantren ini berkomitmen untuk mengembangkan kurikulum Madrasah Hadhramaut pada lembaga dan madrasah diniyahnya.

\section{Sumber data}

Sumber data dalam penelitian ini terbagi menjadi menjadi dua, yaitu sumber data primer dan sumber data sekunder. Sumber data primer diperoleh dari hasil observasi dan wawancara bersama pengurus Pondok Pesantren Darul Faqih Malang.

Sumber data sekunder diperoleh dari dokumentasi berupa dokumen kurikulum dan pendidikan, serta sumber data tertulis yang berkaitan dengan pengembangan kurikulum Madrasah Hadhramaut di Pondok Pesantren Darul Faqih Malang.

\section{Teknik pengumpulan data}

\footnotetext{
${ }^{4}$ Sugiyono, Metode Penelitian Kuantitatif, Kualitatif, dan R\&D (Bandung: Alfabeta, 2008), 70.
} 
Teknik pengumpulan data merupakan langkah yang paling utama dalam penelitian, karena tujuan utama dari penelitian adalah mendapatkan data. Dalam penelitian kualitatif, pengumpulan data dilakukan pada natural setting (kondisi yang alamiah), sumber data primer dan teknik pengumpulan data lebih banyak pada : observasi berperan serta (participan observation), wawancara mendalam (in depth interview) dan dokumentasi. Sedangkan teknik yang digunakan dalam pengambilan data pada penelitian ini adalah observasi, dalam hal ini peneliti akan menggunakan observasi partisipasi moderat. Sesuatu yang akan diobservasi adalah hal-hal yang berkaitan dengan perencanaan, pelaksanaan/praktek di lapangan, dan metode evaluasi pengembangan kurikulum Madrasah Hadhramaut di Pondok Pesantren Darul Faqih Malang.

\section{Analisa data dan pengecekan keabsahan data}

Data tentang pengembangan kurikulum dianalisis secara kualitatif dengan tahap-tahap sebagai berikut: pengumpulan data (analisis data selama proses pengumpulan data), reduksi data, memilah-milah data hasil reduksi dalam satuansatuan (segmentasi data), melakukan atau membangun kategorisasi, dan menarik kesimpulan.

\section{Hasil dan Pembahasan}

\section{Hadramaut dan Hubungannya dengan Nusantara}

Hadramaut, atau Hedramaut atau Havermavt (Bahasa Ibrani) dalam injil ia disebut sebagai Hazarmaveth Genesis:10-26-28, adalah sebuah lembah di negeri Yaman. Lembah ini cukup subur untuk ukuran negeri Yaman yang umumnya padang pasir tandus. Hadramaut merupakan negeri tempat tinggal Nabi Hud dan Saleh. Awal mula julukan Hadramaut masih merupakan perdebatan hingga saat ini. Sebagian kelompok mengambil kisah orang-orang Yunani yang menemukan air di lembah tandus Arabia dan kemudian menamakannya dengan Hydreumata atau sumber air.

Hadramaut dikenal luar oleh masyarakat keturunan Arab di Indonesia. Hampir seluruh masyarakat keturunan Arab di Indonesia nenek moyang mereka berasal dari Hadramaut. Sebelum Perang Dunia ke-II banyak orang mengirimkan anaknya untuk 
belajar ke Hadramaut, sebuah daerah di propinsi Yaman Bagian Selatan. Sayangnya setelah merdeka dari Inggris, Yaman Selatan (masih belum bersatu dengan Yaman Utara) dikuasai oleh komunis. Selama 26 tahun pemerintahan komunis, hubungan antara Hadramaut dengan Indonesia seolah-olah terputus.

Setelah ideologi komunis ditolak rakyat Hadramaut, sejak pertengahan 1990an, seperti meneruskan tradisi di masa lalu, semakin banyak warga Indonesia yang mengirimkan anak-anaknya untuk menempuh pendidikan di wilayah itu. ${ }^{5}$ Beberapa lembaga pendidikan berdiri di Hadramaut, baik formal maupun informal. Lembaga formal misalnya adalah Universitas al-Ahgaff, menyusul kemudian Institut al-Imam alSyafi'i. Sementara lembaga informal misalnya adalah Darul Musthafa, Rubath alHabsyi, dan sebagainya. Lembaga-lembaga ini berdiri, melengkapi khazanah lembaga pendidikan Hadramaut yang telah lama berdiri, lebih dari satu abad lalu, yaitu Rubath Tarim. Maka sejak 1990-an, pelajar dan mahasiswa Indonesia kembali berdatangan ke Hadramaut.

Hubungan Hadramaut dan Nusantara dalam dunia pendidikan dibuktikan pula dengan fakta beberapa ulama Hadhramaut yang merupakan kelahiran Indonesia. Misalnya adalah Grand Mufti Tarim Syaikh Fadhal bin Abdurrahman Ba-Fadhal. Demikian pula sebaliknya, beberapa nama ulama di Indonesia merupakan kelahiran Hadhramaut. Misalnya adalah Sayid Idrus bin Salim al-Jufri, pendiri al-Khairaat Palu Sulawesi yang dilahirkan di Taris, Hadhramaut. Hubungan kedua wilayah dalam dunia pendidikan dapat dilihat pula dalam ranah literasi. Beberapa kitab karya ulama Hadramaut familiar di kalangan pelajar muslim (santri) di Nusantara dan dipelajari di pesantren-pesantren. Misalnya adalah kitab Sullamut Taufiq karya Syaikh Habib Abdullah bin Thahir al-Haddad, kitab Safinatun Najah karya Syaikh Salim bin Sumair al-Hadrami, kitab Busyral Karim karya Syaikh Ba'asyin, kitab Bughyatul Mustarsyidin karya Sayyid Abdurrahman al-Masyhur, Nashaih Diniyah karya Imam Abdullah bin Alwi al-Haddad, dan sebagainya.

Hubungan pendidikan dan dakwah ini telah melahirkan corak yang sama dalam

5 Wikipedia, "Murah dan Bermutu di Hadramaut" (diakses 1 Nopember 2018) https://id.wikipedia.org/wiki/Hadramaut. 
ideologi, madzhab, dan tradisi masyarakat muslim Hadramaut dan Nusantara. Dalam ideologi, mayorittas umat Islam Hadramaut dan Nusantara bermadzhab Asy'ari Maturidi. Dalam madzhab fikih bermadzhab Syafi'i, dengan mengakui keberadaan madzhab-madzhab lainnya. Sementara dalam tradisi dan amaliah keseharian, masyarakat Hadramaut dan Nusantara juga mengamalkan amaliah yang sama. Misalnya pembacaan maulid Nabi, baik ad-Daiba’i karya Sayyid Abdurrahman Ad-Daiba’i dari Yaman, Simtud Dhurar karya Habib Ali bin Husen al-Habsyi dari Hadramaut; pembacaan Ratibul Haddad, al-Wirdu al-Lathif yang disusun oleh al-Imam Abdullah bin Alwi al-Haddad, bahkan "hari raya" 7 Syawal yang dikenal masyarakat Hadramaut dengan istilah 'Uwadh. Termasuk pula pembacaan tahlil sampai 7 hari kematian. Bahkan menurut salah satu kajian NU Klaten, penyusun bacaan tahlil mengerucut pada nama, yaitu al-Bushiri dan al-Habib Abdullah bin Alwi al-Haddad dari Tarim, Hadramaut.

Hubungan jalur sanad pendidikan ini sebenarnya telah diwujudkan di Nusantara dengan berdirinya lembaga-lembaga pendidikan "bernuansa" Hadramaut, baik yang telah lama berdiri maupun masih relatif baru. Misalnya yang telah lama berdiri adalah ribuan pesantren al-Khairat di Palu, yang didirikan oleh Sayyid Idrus bin Salim (SIS) al-Jufri, seorang pria kelahiran Taris, Hadramaut dan pernah diusulkan menjadi pahlawan nasional Indonesia pada era Mensos Salim Segaf al-Jufri. Termasuk pula pesantren Darul Hadits al-Faqihiyah Malang, pesantren yang telah berusia hampir satu abad, didirikan oleh Habib Abdul Qadir Bil Faqih, alumni Rubath Tarim, Hadramaut. Sementara yang bersifat formal adalah lembaga pendidikan al-Khairiyah yang berafiliasi kepada Alawiyin dan lembaga pendidikan al-Irsyad yang berafiliasi kepada masyayikh.

Sementara lembaga pendidikan yang relatif baru adalah pesantren-pesantren yang didirikan oleh masyarakat Arab keturunan Hadramaut atau alumni lembaga pendidikan di Hadramaut. Misalnya adalah pesantren Darul Lughah wa ad-Da'wah yang kini diasuh oleh Habib Zein bin Hasan Baharun, pesantren al-Fachriyah Bogor pimpinan Habib Jindan bin Jindan alumni Darul Musthafa Hadramaut, dan pesantren al-Bahjah Cirebon yang dididirikan oleh Ustadz Yahya Zainul Ma'arif (Buya Yahya) 
yang merupakan alumni Universitas al-Ahgaff Hadramaut. Lembaga-lembaga pendidikan tersebut telah mengkaji kitab-kitab ulama Hadramaut dan mengamalkan tradisi khas masyarakat Hadramaut. Namun-sejauh pengamatan penulis-lembaga tersebut belum secara resmi menyebutkan "Madrasah Hadramaut" sebagai pijakan kurikulumnya. Hal ini berpotensi karena kurikulum Madrasah Hadramaut ini meskipun telah lama lama dipraktikkan di negerinya, namun belum secara akademis dikaji dan dikembangkan.

Adalah Dr. Habib Abu Bakar al-Adni al-Masyhur yang lalu mengenalkan Manhaj Ta'limi Madrasah Hadhramaut (Kurikulum Madrasah Hadramaut) yang dia istilahkan pula dengan al-Madrasah al-Abawiyah (Madrasah Para Leluhur). Secara filosofis dan akademis, peraih gelar honoris causa dari Universitas Aden Yaman ini meneliti dan mengkaji kurikulum tersebut, lalu men-diseminasi pada sekitar 80 lembaga pendidikan di Hadramaut yang dia asuh. ${ }^{6}$ Fenomena inilah yang membuat peneliti tertarik untuk melakukan kajian terhadap kurikulum ini, dengan studi kasus Pondok Pesantren Darul Faqih Malang, Jawa Timur (putra dan putri).

\section{Karakteristik Utama Madrasah Hadramaut}

Abu Bakar al-Adni memiliki sebuah kitab berjudul al-Dalail al-Nabawiyah alMu'abbirah 'an Syaraf al-Madrasah al-Abawiyah. Kitab ini merupakan hasil pemikiran filosofis tentang pentingnya konsep Madrasah Abawiyah dan bagaimana menerapkannya dalam lembaga pendidikan. Pada bagian akhir kitabnya, al-Adni menyebut bahwa Madrasah Hadramaut adalah representasi dari Madrasah Abawiyah itu. ${ }^{7}$ Perlu ditekankan bahwa istilah "Madrasah Hadramaut" tidak menunjuk langsung sebuah lembaga di Hadramaut. Namun bermula dari Hadramaut sebagai sebuah wilayah dengan segala karakteristik pendidikan yang berlaku di sana, lalu dikonsepsikan atau dirumuskan kembali dalam aplikasi pada lingkup keluarga, masyarakat, lalu lembaga pendidikan.

Maka pada bukunya, mula-mula al-Adni menyoroti model pendidikan yang berlaku di Hadramaut. Model pendidikan yang dimaksud bukanlah yang telah

6 Zainal Abidin Bil Faqih, Wawancara, STAI Dalwa Bangil Pasuruan, Nopember 2018.

7 Abu Bakar al-Adni bin Ali al-Masyhur, al-Dalail al-Nabawiyah al-Mu'abbirab 'an Syaraf al-Madrasah al-Abawiyah (Aden Yaman: Marzak al-Ibda’ al-Tsaqafi, 2010), 66. 
terpraktikkan di lembaga-lembaga resmi pendidikan di wilayah itu. Namun bagaimana konsep itu berjalan pada hubungan guru dengan murid, orang tua dengan anak, atau halaqah-halaqah yang ada di masjid atau zawiyah. ${ }^{8}$ Secara panjang lebar, al-Adni menarasikan karakteristik Madrasah Abawiyah tersebut. Secara ringkas karakteristik itu adalah sebagai berikut:

a. Sambungnya transmisi sanad keilmuan (al-Isnad wa al-Asanid). ${ }^{9}$ Al-Adni dalam hal ini menekankan pentingnya sanad dalam pendidikan, terutama dalam hal-hal ilmu syariat. ${ }^{10}$

b. Pembiasaan ibadah dan pendidikan karakter pada masa pertumbuhan (al-ta'abbud wa al-suluk fi adab al-tansyiah). Al-Adni dalam poin ini merilis tentang beberapa dalil dan argumentasi tentang pentingnya pembiasaan ibadah dan akhlak yang baik sejak dini.

c. Pelestarian terhadap ajaran dan tradisi baik leluhur. Poin ini merupakan hal inti dalam konsep yang dia tawarkan, karena itulah dia menamakannya dengan Madrasah Abawiyah (Madrasah Para Leluhur). Telah maklum bahwa leluhur yang dimaksud adalah keturunan atau dzurriyah Nabi Muhammad Shallallahu 'Alaihi Wasallam. Hadramaut adalah wilayah yang banyak dihuni oleh keturunan Nabi Muhammad, sejak hijrahnya Ahmad bin Isa al-Muhajir dari Bashrah ke Hadramaut pada abad ke-4 hijriyah. Melalui validasi nasab, Ahmad bin Isa adalah keturunan ke-9 Nabi Muhammad dan merupakan salah seorang naqib (ketua keluarga keturunan Nabi).11

d. Melakukan antisipasi terhadap pengaruh politik dalam dunia pendidikan (alManhaj al-Musayyas). Terdapat potensi yang dimaksud oleh al-Adni bukanlah pengaruh politik secara umum, namun maksudnya adalah pengaruh gesekan dan konflik politik yang bisa saja berpengaruh tidak baik terhadap dunia pendidikan. Karena yang dia contohkan adalah pengaruh imperialisme yang berdampak pada

\footnotetext{
8 Zawiyah adalah ruangan yang biasanya berada di pojok masjid. Karena itulah ruangan ini disebut dengan zawiyah yang berarti pojok. Sebelum berdirinya lembaga-lembaga pendidikan baik formal maupun non formal, pendidikan di Hadramaut berlangsung di zawiyah-zawiyah ini (lihat: al-Khafaya fi al-Zawaya).

${ }^{9}$ Abu Bakar al-Adni, al-Dalail al-Nabawiyah, 13.

10 Abu Bakar al-Adni, al-Dalail al-Nabawiyah, 60.

${ }^{11}$ Faris Khoirul Anam, Abmad bin Isa al-Muhajir: Lelubur W alisongo dan Habaib di Indonesia.
} 
campurnya siswa dan siswi dalam satu ruangan kelas, pengurangan materi ilmu syari'ah di sekolah-sekolah, dikotomi antara pendidikan (tarbiyah) dan pengajaran (ta'lim) dalam semua kurikulum sekolah. ${ }^{12}$

e. Penguatan learning society. Pendidikan "konsep leluhur" (abawiyah) telah mengkristal menjadi tradisi baik dan menciptakan iklim pendidikan yang ideal di Hadramaut. Peran serta masyarakat dalam membentuk karakter peserta didik adalah sebuah keniscayaan dengan tetap mengantisipasi pengaruh tidak baik dari luar sebagai dampak globalisasi dan kemajuan tekhnologi informasi.

f. Konsep pendidikan idealnya dihubungan dengan Figh Tahawwulat. Al-Adni adalah seorang pemikir muslim yang berkonsentrasi pada fikih dinamisasi zaman atau fiqh tahawwulat. Ia melakukan autokritik terhadap pemahaman umat Islam selama ini bahwa rukun-rukun agama terbatas pada tiga hal, yaitu rukun Iman, Islam, dan ihsan. Padahal sesuai hadits Jibril, setelah Nabi Muhammad ditanya tentang iman, Islam, dan ihsan, beliau setelah itu ditanya tentang tanda-tanda kiamat. Poin-poin inilah yang selama ini "lepas" dari fokus kajian umat. Padahal semua hal yang terjadi di dunia ini tidak lepas dari dinamisasi zaman. Sementara ayat-ayat alQur'an dan hadits-hadits Nabi memiliki sekian penjelasan tentang dinamisasi zaman itu. Al-Adni membagi masa umat Nabi Muhammad menjadi lima, diawali dengan masa pengkabaran (istikhbar) dan diakhiri dengan masa pembuktian (istitsmar) dari hal-hal yang sudah dikabarkan oleh Nabi Muhammad.

g. Universalitas konsep Madrasah Abawiyah. Al-Adni menekankan bahwa konsep pendidikan ini telah terbukti diterima masyarakat global. Diawali dengan hijrahnya Ahmad bin Isa dari Bashrah ke Hadramaut untuk membawa ajaran leluhur, lalu didakwahkan di Hadramaut. Pada era berikutnya beberapa bukti mendalilkan bahwa penyebaran Islam di berbagai wilayah di dunia adalah berkat misi dakwah para da’i Hadramaut. Misalnya di kawasan Sawahil, Juzrul Qamar, Tanzania, Afrika Selatan di benua Afrika; serta pesisir India, kepulauan Indonesia, Malaysia, dan Singapura di benua Asia. Di daerah-daerah tersebut sampai saat ini terdapat jejak-jejak dakwah para da’i Hadramaut, baik berupa lembaga pendidikan,

12 Abu Bakar al-Adni, al-Dalail al-Nabawiyah, 14-15. 
keyakinan madzhab teologi, pengamalan madzhab fikih, dan pelestarian tradisitradisi pembacaan maulid, ratib, dan sebagainya. ${ }^{13}$

Pada bagian berikutnya, al-Adni mengkaji fenomena konsep madrasah ini dari yang asalnya "da'wah ila al-dzat" menuju "al-muassasat", terutama sejak maraknya pendirian lembaga pendidikan di Hadramaut pada 1990-an. Maksudnya adalah bagaimana menerjemahkan pendidikan dan dakwah Islam masyarakat Hadramaut itu dalam kurikulum di lembaga-lembaga pendidikan. Terdapat dua hal yang kemudian menurutnya musti diperhatikan saat ini, yaitu (1) madrasah sebagai buah pemikiran dan strategi dan (2) metode sebagai cara dan pengajaran. 14 "Jahitan" masing-masing poin dalam konsep itu adalah kecermatan dalam menganalisa isu-isu agama, sejarah, dan politik. Dengan terus mengembangkan dan mengkaji masing-masing isu tersebut, generasi muslim akan terus tersambung dengan prinsip Islam, baik secara akidah, akhlak, ushul, dan fikih. Al-Adni menjelaskan, kajian tentang substansi pendidikan itu harus selalu memperhatikan beberapa hal sebagai berikut:

Kajian yang memperhatikan dinamisasi zaman dan tanda-tanda kiamat (fiqh tahawwulat), Kajian yang memperhatikan sejarah dinamisasi politik umat, Kajian yang memperhatikan metode berbasis dakwah, syari'ah, madzhab, shufi, salaf, dan hubungannya dengan "tekanan” politik luar, baik dalam bentuk penjajahan fisik atau lainnya. ${ }^{15}$

Setelah melalui penelusuran dan kajian panjang, baik tentang tantangan penerapan konsep pendidikan ini, percobaan pada lembaga pendidikan dan bidangbidang keilmuan yang dipelajari, al-Adni menutup kajiannya dengan logo atau syi'ar bagi konsep Madrasah Hadramaut yang dia kembangkan. Ia sekaligus menjelaskan makna masing-masing bagian dari logo tersebut.

13 Sugiyono, Metode Penelitian Kuantitatif, Kualitatif, dan R\&D, 73-76.

${ }^{14}$ Sugiyono, Metode Penelitian Kuantitatif, Kualitatif, dan R\&D, 97.

15 Andi Prastowo, Metode Penelitian Kualitatif Dalam Perspektif Rancangan Penelitian, 102. 


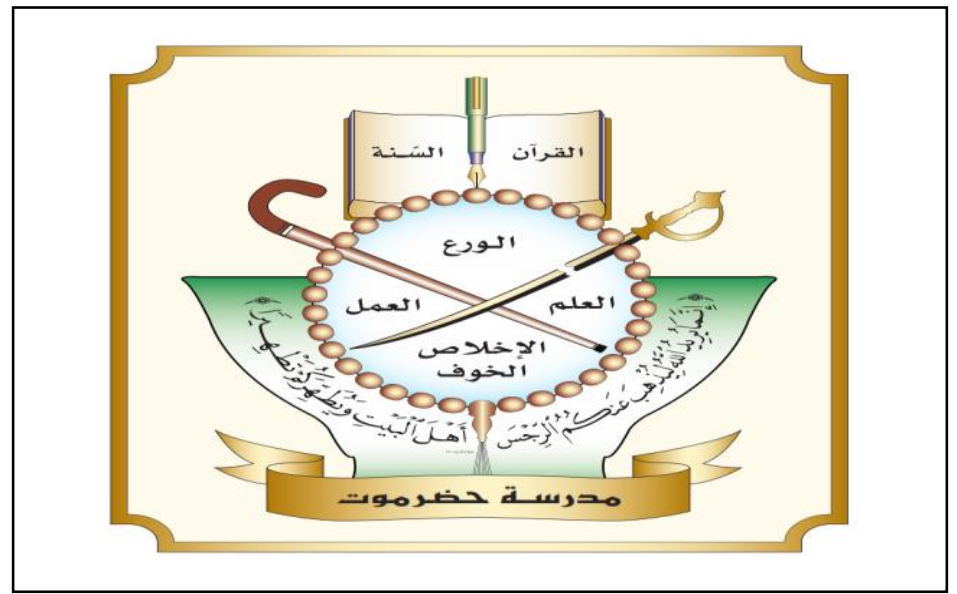

Gambar 1. Logo (Syi'ar) Madrasah Hadramaut

\section{Pondok Pesantren Darul Faqih Malang dan Model Pengembangan \\ Kurikulum Madrasah Hadramaut}

Pondok Pesantren Darul Faqih adalah pesantren yang baru didirikan pada tahun 2016. Pembangunan dan proses pendidikan berjalan bersama, yang diawali dengan majlis taklim sejak 2016, lalu Madrasah Diniyah Permata Darul Faqih (PDF) dan penerimaan santri menetap sejak 2018. Model pengembangan kurikulum Madrasah Hadramaut, yang meliputi perencanaan, pelaksanaan, dan evaluasi, diikhtiarkan untuk dilakukan di pesantren yang pembangunannya mendapatkan restu dari Rektor Universitas al-Ahgaff Hadramaut Yaman. Hal itu ditandai dengan kehadirannya pada peletakan batu pertama dan penandatanganan prasasti.

Penamaan Darul Faqih sendiri telah paralel dengan konsep pendidikan atau kurikulum Madrasah Hadramaut. Apabila diartikan secara literal, "Darul Faqih" memang berarti "Rumah Ahli Fikih" atau "Rumah Ahli Agama". Namun selain itu, Darul Faqih adalah nama sebuah bangunan yang ada di Tarim, Hadramaut, Yaman. Gedung ini berada di antara Masjid Ba'alawi dan Masjid as-Saggaf, serta berdekatan dengan Rubath Tarim saat ini. Kata "Faqih" dinisbatkan kepada Sayyidinal Faqih alMuqaddam Muhammad bin Ali Ba'alawi. Beliau diberi gelar al-faqih al-muqaddam, karena di antara ulama Hadramaut pada kisaran abad ke lima dan enam hijriyah, beliau adalah ahli agama (al-faqih) yang selalu diutamakan (al-muqaddam). "Darul Faqih" adalah "Rumah al-Faqih" ini. Bangunan yang terus dilestarikan ini sekarang tetap 
menjadi tempat kajian kitab-kitab oleh para penuntut ilmu, bahkan menjadi pertemuan para mufti kota Tarim dalam pembahasan-pembahasan masalah keagamaan.

Al-Faqih al-Muqaddam memiliki hubungan dengan Walisongo. Secara garis keturunan, al-Faqih al-Muqaddam Muhammad bin Alwi Ba 'Alawi memiliki paman bernama Sayyid Alwi bin Muhammad Shahib Mirbath. Sayyid Alwi atau Ammul Faqih (paman dari al-Faqih) yang wafat di Tarim pada $613 \mathrm{H}$ ini memiliki seorang putra bernama Sayyid Abdul Malik. Itu artinya, al-Faqih al-Muqaddam adalah sepupu dari Sayyid Abdul Malik bin Alwi bin Muhammad Shahib Mirbath tersebut. Sementara membicarakan Walisongo di Indonesia tentu tak akan lepas dari sosok Sayyid Abdul Malik ini. Beliau adalah keturunan ke delapan dari al-Imam al-Muhajir Ahmad bin Isa, seorang sayyid keturunan ke sembilan Nabi Muhammad yang berhijrah dari Bashrah, Irak ke Hadramaut, Yaman pada abad ke empat hijriyah.

Sayyid Abdul Malik bergelar al-Muhajir al-Tsani atau orang kedua dari keturunan Nabi yang berhijrah setelah Imam Ahmad bin Isa. Apabila Imam Ahmad bin Isa berhijrah dari Basrah, Irak ke Hadramaut sehingga di salah satu wilayah Yaman ini banyak terdapat keturunan Nabi Muhammad, maka di masa berikutnya Sayyid Abdul Malik berhijrah dari Hadramaut ke India, sehingga di India lalu Asia Tenggara banyak terdapat keturunan Nabi Muhammad, termasuk para da'i di Nusantara yang dikenal dengan nama Walisongo.

Sebab menikah dengan putri bangsawan Naserabad (Nashr Abad) yang bermarga Khan, Sayyid Abdul Malik berhak digelari Khan. Namun mengingat Sayyid Abdul Malik berasal dari keturunan al-Husain putra Fathimah binti Rasulillah, maka mereka menambahkan kata "Azmat" sebelum "Khan". Dalam bahasa Urdu India, "Azmat" sama dengan "Syarif', yaitu mulia. Maka terbentuklah sebuah kalimat “Azmatkhan”. Sayyid Abdul Malik Azmatkhan sendiri merupakan penyebar Islam di India. Beliau memiliki banyak putera. Putera sulungnya, Abdullah, pernah menjadi menteri dan delegasi Kerajaan Naserabad ke negeri-negeri timur. Bahkan beliau sempat bersaing dengan Marcopolo di daratan China. Abdullah Azmatkhan memiliki seorang putera bernama Ahmad Jalaluddin.

Muhammad Mais bin Hasan dalam Keturunan Sebagian Besar Walisongo 
(artikel dimuat Media Umat, Edisi 66/tahun III) menjelaskan, salah satu cucu Abdul Malik bin Alawi ini merupakan salah satu dari Walisongo yang masyhur di Indonesia. Dari Ahmad bin Abdullah bin Abdul Malik ini pula lahir keturunan Azmatkhan di Indonesia, melalui dua orang putera beliau, yakni Husain Jamaluddin dan Sulaiman alBaghdadi. Sayyid Jamaluddin al-Husain oleh sebagian orang Jawa disebut Syaikh Jumadil Kubra. Sedangkan saudaranya, Sulaiman, diberi nama al-Baghdadi karena diprediksi pernah tinggal lama di Baghdad. ${ }^{16}$

Pondok Pesantren Darul Faqih yang berada di bawah Yayasan Darul Faqih Indonesia berdiri di desa Pandanlandung, Kecamatan Wagir, Kabupaten Malang. Kampus ini khusus untuk menampung santri putra dan kegiatan pembelajarannya telah berjalan 1,5 tahun untuk majlis taklim, dan 1 semester untuk Madrasah Diniyah baik untuk santri menetap maupun tidak menetap (santri manuk). Sedangkan untuk santri putri diproyeksikan menetap di bangunan asrama yang diwakafkan kepada Yayasan Darul Faqih, terletak di Kelurahan Polehan, Kecamatan Blimbing, Kota Malang. Perencanaan, pelaksanaan, dan evaluasi kurikulum Madrasah Hadramaut di Pesantren Darul Faqih berada di bawah "payung" visi misi pesantren sebagai berikut:

Visi : Menjadikan Darul Faqih sebagai pesantren unggul yang memiliki daya saing dan daya juang tinggi, untuk melahirkan generasi berkarakter islami, memiliki kesalihan pribadi dan sosial, dan komitmen mendakwahkan Islam sebagai rahmatan lil ‘alamin.

Misi:

a. Melestarikan nilai al-Qur'an, Sunnah Nabi, dan ajaran para ulama Ahlussunnah Wal-Jama'ah.

16 Untuk lebih memperjelas hubungan antara Sayyid Abdul Malik dengan sebagian besar Walisongo di Indonesia, dapat diperhatikan silsilah tokoh-tokoh era Walisongo, baik di buku-buku yang ada maupun di silisah garis keturunan (sanad) yang ada di makam-makam mereka di Jawa Salah satu contohnya adalah nasab Sunan Bonang. Beliau yang bernama asli Sayyid Ibrahim adalah putra Ahmad Rahmatullah (Sunan Ampel) bin Ibrahim bin Husain Jamaluddin bin Ahmad Jalaluddin Abdullah bin Abdul Malik Azmatkhan bin Alwi ('Ammul Faqih), yang selanjutnya bersambung kepada al-Imam al-Muhajir Ahmad bin Isa.

Itu artinya, Sunan Ampel adalah keturunan ke-4 atau cicit dari Sayyid Abdul Malik bin Ammul Faqih ini. Sementara Sunan Bonang adalah keturunan ke-5, demikian pula putra beliau yang lain yaitu Sunan Drajat atau Sayyid Qasim. Sunan Giri atau Muhammad Ainul Yaqin yang merupakan "dua pupu" Sunan Ampel (sama-sama cucu dari Sayyid Husain Jamaluddin) merupakan keturunan ke-5 Sayyid Abdul Malik bin Ammul Faqih. Sunan Gunung Jati atau Syarif Hidayatullah yang merupakan cicit Sayyid Husain Jamaluddin adalah keturunan ke-6 Sayyid Abdul Malik bin Ammul Faqih. Demikian pula anggota Walisongo yang lain, mereka bernasab kepada Sayyid Abdul Malik bin Ammul Faqih, dan tentunya kepada al-Imam al-Muhajir Ahmad bin Isa dan seterusnya sampai kepada Nabi Muhammad Shallallahu 'Alaihi Wasallam. 
b. Mengembangkan pendidikan dan dakwah Islam.

c. Mempersiapkan generasi yang memahami keilmuan agama (tafaqquh fi al-din), berkepribadian islami, memiliki profesionalisme dan integritas.

\section{Perencanaan}

Perencanaan kurikulum Madrasah Hadramaut di Pondok Pesantren Darul Faqih didorong oleh beberapa motif dan argumentasi:

a. Pertama, model pendidikan Hadramaut adalah pendidikan yang harmoni dan moderat. Hal ini ditunjukkan dengan peristiwa "Kasr Saif' oleh al-Faqih alMuqaddam. Termasuk pula dibuktikan dengan penerimannya terhadap tradisi yang baik, bahkan Madrasah Hadramaut melestarikannya. Tradisi habaib dikembangkan, demikian pula tradisi Walisongo yang notabene juga keturunan para ulama Hadramaut.

b. Kedua, sesuai observasi, selama ini terdapat "ceruk" kesenjangan yang belum terisi oleh pesantren-pesantren. Hal itu dilihat dari output alumni yang melanjutkan studinya ke Hadramaut Yaman. Alumni Pesantren salaf kuat dalam pemahaman fikih namun relatif lemah dalam pengausaan bahasa Arab terutama kompetensi tulis dan bicara (maharat al-kitabah dan maharat kalam). Sementara alumni Pesantren khalaf kuat dalam penguasaan bahasa, namun cenderung lemah dalam penguasaan fikih. Pelaksanaan kurikulum Madrasah Hadramaut salah satunya memang bertujuan untuk menyiapkan para santri yang berkeinginan melanjutkan belajarnya ke Hadramaut. Namun tentunya hal ini bukan tujuan satu-satunya. Sehingga seandainya mereka tidak melanjutkan studinya ke negeri itu, kurikulum juga secara otomatis telah membekali mereka keilmuan-keilmuan yang bermanfaat di tengah masyarakat.

c. Ketiga, pengembangan kurikulum Madrasah Hadramaut di Pesantren Darul Faqih meruapakan bagian dari ikhtiar untuk melembagakan kurikulum Madrasah Hadramaut dan untuk menjaga hubungan tradisi keilmuan antara kedua wilayah. Hal ini perlu ditegaskan karena tidak menutup kemungkinan terdapat kesamaan materi-materi kitab yang dikaji dalam pelaksanaan kurikulum lainnya

Secara umum, model pengembangan kurikulum Madrasah Hadramaut di Darul 
Faqih tentunya akan mengalami modifikasi pada bagian tertentu yang diperlukan. Hal ini terjadi karena beberapa hal. Misalnya, pertama, penguasaan ilmu alat yang berbeda. Para peserta didik di Hadramaut sedikit banyak telah menguasai bahasa Arab karena memang menjadi bahasa ibunya, sementara peserta didik di Indonesia tentu masih memerlukan waktu dan proses pengajaran ilmu alat ini. Kedua, perbedaan kekuatan learning society antara masyarakat Hadramaut dan masyarakat di sekitar pesantren Darul Faqih. Ketiga, pemadatan materi, karena durasi penerapan kurikulum di Darul Faqih tentunya lebih singkat, sebab masih terdapat waktu khusus untuk meguasai ilmuilmu alat pada tiga tahun pertama. Beberapa kebijakan dapat diambil, misalnya matanmatan ilmu yang harus dihapal pada tiga tahun kedua, telah dibaca dan diulang-ulang oleh para santri pada tiga tahun pertama, misalnya dengan dipergunakan sebagai pujian-pujian (bacaan antara adzan dan iqamah) shalat.

\section{Pelaksanaan}

Pelaksanaan kurikulum secara umum terbagi menjadi dua tahap. Tahap pertama selama tiga tahun pertama dan tahap kedua pada tiga tahun kedua. Total terdapat enam tahun masa pembelajaran atau penerapan kurikulum:

a. Tiga tahun pertama pendidikan di Darul Faqih memfokuskan diri pada penguasaan santri terhadap dasar-dasar keilmuan Islam, meliputi al-Qur'an (tahsin dan tahfizh), Bahasa Arab (maharat al-qira'ah, maharat al-kalam, maharat al-kitabah, maharat sima'ah)+Nahwu. Diharapkan santri telah mampu membaca kitab, mampu menulis/menyusun materi berbahasa Arab, mampu memahami ungkapan lisan berbahasa Arab, dan mampu berbicara menggunakan Bahasa Arab. Kemampuan-kemampuan tersebut adalah penguasaan dasar, sebelum memasuki program tiga tahun kedua.

b. Tiga tahun kedua pendidikan di Darul Faqih mulai secara spesifik menggunakan kurikulum Madrasah Hadramaut. Harapannya, santri yang terdorong dan berminat untuk melanjutkan studi ke Hadramaut Yaman telah memiliki penguasaan dan pengalaman ilmiah. Darul Faqih bertugas menyiapkan para calon pelajar atau mahasiswa sekaligus membuka jalur-jalur pendidikan di luar negeri itu, untuk mengisi ceruk kekosongan belum - atau sedikitnya pesantren, yang 
memfokuskan diri untuk menyiapkan santri yang berminat melanjutkan studinya di negeri Arab, dalam hal ini Hadramaut Yaman. Sedangkan yang belum berkesempatan melanjutkan studi ke Hadramaut, pendidikan di Darul Faqih secara otomatis diharapkan dapat pula menjadikan mereka generasi yang siap berkiprah di tengah masyarakat.

Meskipun Pesantren Darul Faqih tidak mengkhususkan diri sebagai pesantren tahfizhul Quran, namun untuk menjaga perilaku dan qolbun salim (hati yang sehat), setiap santri akan dibimbing untuk menghafalkan al-Quran dengan metode One Day Three Lines (ODTL). Dalam bahasa aplikatif, santri akan dibimbing untuk meghafalkan al-Quran tiga baris dalam setiap hari yang telah ditentukan. Metode ODTL akan dikhususkan dengan menggunakan Mushaf Rasm Utsmani sebagai acuan pengaplikasian dan pencapaian. Dengan metode One Day Three Lines ini diharapkan santri akan tetap nyaman serta tidak merasa terbebani dengan berbagai aktifitas belajar yang lain, baik di pesantren maupun di sekolah. Dengan menggunakan metode ini, dalam satu semester santri dapat menghafalkan satu juz al-Qur'an. Dengan asumsi masa pendidikan di Darul Faqih selama 6 tahun (12 semester), maka santri Darul Faqih telah memiliki bekal hafal al-Qur'an sebanyak 10 juz, jumlah hapalan terstandar bagi mahasiswa S1 di beberapa universitas di negara-negara Arab, termasuk di Hadramaut. Selain itu, bekal hapalan 10 juz diharapkan menjadi perangsang atau stimulus bagi mereka untuk melengkapi hapalannya di kemudian hari.

Sementara dalam upaya membentuk learning society, di Darul Faqih terdapat 3 kajian untuk masyarakat "non-santri” menetap. Kajian pertama adalah Majelis Taklim "Sehidup Se-Surga" tiap Ahad pagi untuk masyarakat umum. Materinya adalah pembacaan Ratib al-Haddad serta Kajian Fikih dan Dialog. Kajian kedua adalah Majelis "Katakan Cinta" (kepanjangan dari Kajian tentang Akidah Amaliyah anNahdliyah dan Cerita Indah tentang Apa Saja) tiap Rabu malam untuk para remaja putra dan putri. Materinya adalah kitab Safinatun Najah dan Sullamut Taufiq. Kajian ketiga adalah Fikih Parenting tiap Ahad malam Senin tiap awal bulan untuk para wali santri, baik wali santri Madrasah Diniyah Pertama Darul Faqih maupun wali santri dari santri menetap. Materinya adalah kitab Kaifa Nurabbi Auladana Tarbiyatan Islamiyatan 
Shabihatan karya Syaikh Mahmud al-Mishri.

\section{Evaluasi}

Pelaksaan kurikulum tersebut sampai saat ini masih berjalan dua semester. Penerapan kurikulum Madrasah Hadramaut juga masih dalam tahap persiapan, karena secara spesifik dapat diterapkan pada tiga tahun kedua. Sebagai materi evaluasi, selama ini telah ada 11 calon pelajar atau mahasiswa yang berminat untuk melanjutkan studi ke Hadramaut dan telah mengikuti persiapan secara intensif di Pondok Pesantren Darul Faqih. Mereka berasal dari Pesantren Nurul Islam (Nuris) Jember, Pesantren Ilmu alQur'an (PIQ) Singosari Malang, Pesantren Hidayatul Qur'an Singosari Malang, Pesantren Nurul Ulum, Kacuk, Kebonsari, Malang, Pondok Pesantren Darut Tauhid Malang, Pesantren Mathali'ul Falah, Kajen, Pati, Jawa Tengah dan Pondok Pesantren an-Nur al-Zubaidi, Meluhu, Sulawesi Tenggara.

Para santri putra dan putri tersebut mengikuti pendalaman materi Fikih dan Bahasa Arab, baik penguasaan lisan dan tulisan. Dari 11 calon pelajar dan mahasiswa tersebut, 9 di antaranya lolos seleksi masuk perguruan tinggi di Hadramaut Yaman dan kini telah belajar di negeri tersebut. Sementara 2 orang masih belum berhasil lolos seleksi. Hasil ini menjadi bahan evaluasi pengurus untuk selanjutnya diterapkan pada para santri menetap yang sejak awal belajar di Pondok Pesantren Darul Faqih, di mana pada tiga tahun pertama mereka mempelajari Bahasa Arab dasar dan ilmu alat lainnya, terutama dalam empat keahlian, yaitu keahlian membaca (maharat al-qira'ah), keahlian menulis (maharat al-kitabah), keahlian menyimak (mabarat al-istima), dan keahlian berbicara (maharat al-kalam). Sementara pada 3 tahun kedua mereka mempelajari subject matter atau bahan/ mata pelajaran khas kurikulum Hadhramaut.

Analisa dan evaluasi ini berguna ke depannya karena salah satu tujuan Darul Faqih menerapkan kurikulum Madrasah Hadhramaut adalah "memposisikan" diri sebagai tempat bagi para santri tersebut untuk mempersiapkan diri dalam studi lanjut ke Hadhramaut. Temuan-temuan pada penelitian mengarah kepada evaluasi yang berada dalam tahap observasi pengurus terhadap pembelajaran selama ini, baik kepada calon pelajar ke Hadhramaut dari pesantren lain di luar Darul Faqih, maupun yang selama 6 (enam) tahun mereka belajar di Darul Faqih, serta diskusi dengan beberapa 
guru alumni Hadhramaut yang mengajar di Darul Faqih, tentang kondisi dan kemampuan pelajar Indonesia di wilayah Yaman bagian selatan itu.

Menurut kesimpulan Kepala Madrasah Diniyah Darul Faqih Ustadz Wahyu Ramdana, selama ini terdapat semacam "kekosongan" atau ceruk di antara pesantrenpesantren yang ada. Dia menyimpulkan hal tersebut sesuai observasi terhadap alumni pesantren tersebut secara umum, observasi terhadap kesebelas calon pelajar dan mahasiswa yang selama ini mengikuti studi persiapan tes ke Hadhramaut di Darul Faqih, serta sesuai diskusi dengan para alumni Hadhramaut yang mengajar di Darul Faqih Malang. Satu sisi, pesantren model salaf alumninya kuat dalam keilmuan fikih, namun belum begitu kuat dalam penguasaan Bahasa Arab aktif, terutama dalam hal keahlian menyimak, menulis, berbicara bahasa Arab, meskipun mereka telah mumpuni dalam keahlian membaca teks Arab. Sedangkan keahlian menyimak, menulis, dan berbicara bahasa Arab tersebut dibutuhkan oleh para pelajar Indonesia yang meneruskan studinya di Hadhramaut, Yaman.

Sementara pesantren model khalaf, kuat dalam keahlian berbahasa Arab aktif, yaitu menyimak, menulis, dan berbicara bahasa Arab, namun belum begitu kuat dalam penguasaan fikih. Sedangkan materi-materi pembelajaran di Hadhramaut-seperti muatan materi belajar di pesantren salaf di Indonesia pada umumnya-banyak berorientasi pada fikih (figh oriented). Hal ini lah yang menjadi temuan utama peneliti dalam kajian ini. Pondok Pesantren Darul Faqih Malang dengan ikhtiarnya untuk mengembangkan kurikulum Madrasah Hadhramaut-meskipun masih dalam tahap merencanakan, mempersiapkan dan terus melakukan evaluasi-berpotensi dapat menjadi jawaban atas kesenjangan yang terjadi selama ini pada pelajar dan mahasiswa Indonesia di Hadhramaut Yaman, yakni terkait "ketimpangan" penguasaan antara keilmuan bahasa Arab dan fikih.

Sementara secara umum, dalam arti bagi alumni yang tidak meneruskan studi ke Hadhramaut, Yaman, maka Pondok Pesantren Darul Faqih Malang melalui kurikulum Madrasah Hadhramaut-nya menjadi salah satu lembaga yang dapat menguatkan pendidikan harmoni dan moderat di Nusantara. Hal itu tercermin paling tidak dalam dua hal, yaitu: Pertama, dalam filosofi 'pecahnya pedang' atau kasr saif 
dalam logo Madrasah Hadhramaut. Kedua, dalam sejarah dan hubungan historis Hadhramaut dan Nusantara, sejak era Walisongo hingga dalam hubungan dakwah kedua wilayah sampai saat ini. Sejarah telah membuktikan bahwa dakwah dan pendidikan yang mereka kembangkan bernuansa harmoni, moderat, dan menghargai kearifan lokal (local wisdom) masyarakat Nusantara.

Evaluasi pengurus Darul Faqih dalam ranah ini terletak pada peningkatan, pendalaman dan studi-studi lanjutan tentang Hadhramaut dan karakteristik pendidikannya. Untuk kepentingan ini, pengurus Pondok Pondok Pesantren Darul Faqih membentuk Pusat Kajian Pengembangan Kurikulum Madrasah Hadhramaut yang diketuai oleh guru Darul Faqih, Ustadz Rizal Ramadhan, yang merupakan alumni Universitas al-Ahgaff Hadhramaut Yaman.

\section{Simpulan}

Berdasarkan uraian dan analisis sebagaimana tersebut diatas, dapat dikemukakan beberapa kesimpulan, yaitu: model pengembangan kurikulum madrasah Hadramaut di pondok pesantren Darul Faqih Malang efektif dilakukan karena dengan adanya pengembangan kurikulum, maka proses pembelajaran di pondok pesantren lebih tersusun rapi dan bagi yang ingin melanjutkan studi juga difasilitasi oleh pondok pesantren untuk pengembangan diri dan keilmuan.

\section{E. Daftar Pustaka}

Abdul, Asrofi. Model-Model Pengembangan Kurikulum, pada uny.ac.id

Al-Adni, Abu Bakar bin Ali al-Masyhur, al-Dalail al-Nabawiyah al-Mu'abbirab 'an Syaraf alMadrasah al-Abawiyah (Aden Yaman: Marzak al-Ibda' al-Tsaqafi, 2010).

Anam, Faris Khoirul. Imam Muhajir Abmad bin Isa: Leluhur Walisongo dan Habaib di Indonesia (Malang: Darkah Media, 2016)

Andi Prastowo, Metode Penelitian Kualitatif Dalam Perspektif Rancangan Penelitian (Jogjakarta: Ar-Ruzz Media, 2012)

Azmatkhan, Muhammad Mais. Ikatan Keluarga Azmatkhan al-Husaini di Indonesia - Keturunan Sebagian Besar Walisongo, Artikel, dimuat Media Umat, Malang, Edisi 66/tahun III, Mei 2009/Jumadil Ula 1430 H.

Berg, Van den. Le Hadhramouth et les Colonies dan I'Archiple Indien (Batavia: Impremerie du Gouvernment, 1886). 
Kesheh, Natalie Mobini. Hadrami Awakening - Kebangkitan Hadhrami di Indonesia (Jakarta, Akbar Media Eka Sarana, 2007)

Muhtifah, Lailial. Pola Pengembangan Kurikulum Pesantren (Kasus Al-Mukblishin Mempawah Kalimantan Barat) (Jurnal MP Vol XVII No 2 2012).

Prasetyo, Agus. Implementasi Pengembangan Kurikulum di Pondok Pesantren (Studi Multisitus di Pesantren al-Aqobah dan Pesantren Tarbiyatun Nasyi'in Pacul Gowang Kabupaten Jombang) (Jurnal Iqra: Kajian Ilmu Pendidikan E-ISSN: 2548-7892 \& P - ISSN: 2527-4449 Volume 3, Issue 2, December 2018).

Prasetyo, Dedy. Implementasi Prinsip at-Tawazun Perspektif Ablus Sunnab Wal Jama'ah An Nahdiyah dalam Pengembangan Nilai Pendidikan Karakter Siswa Di Madrasah Aliyah Al Azhar Banjarwati Paciran Lamongan (Jurnal Akademia, Vol 10, No 2, Desember 2012).

Syahab, Alwi. Hadhramaut dan Koloni Arab, HU Republika, 13 Oktober 2002.

Thohir, Kholis Kurikulum dan Sistem Pembelajaran Pondok Pesantren Salafi di Kecamatan Kresek Kabupaten Tangerang Provinsi Banten (Analytica Islamica: Vol. 6 No. 1 Januri-Juni 2017).

Wahyudin, Didin. Pendidikan Aswaja Sebagai Upaya Menangkal Radikalisme (Dinamika Penelitian: Media Komunikasi Sosial (Vol. 17, No. 2, November 2017).

WP, Sucihatiningsih Dian dan Moh Yasir Alimi, Pembentukan Karakter Nasionalisme melalui Pembelajaran Pendidikan Aswaja pada Siswa Madrasah Aliyah Al Asror Semarang (Journal of Educational Social Studies / JESS 6 (1), 7 - 19 Universitas Negeri Semarang, 2017). 